\title{
HIGH INCIDENCE OF MICROBLEEDS ON SWI BRAIN MRI IN QATAR INTRACEREBRAL HEMORRHAGE POPULATION
}

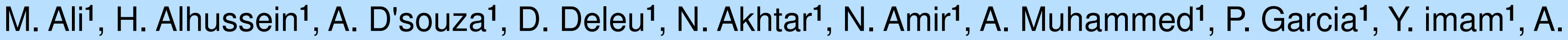 \\ Elsotouhy', P. Bourke1, M. Santos ${ }^{1}$, A. Own1, A. Shuaib¹, M. Saqqur1. \\ 1-Hamad General Hospital, Neurology, Doha, Qatar
}

\section{Background}

Cerebral microbleed (CMB) on brain $\mathrm{MRI}$ is seen in higher frequency in patients with hypertension and may increase risk of intracerebral hemorrhage $(\mathrm{ICH})$ Our study's aim was to evaluate the incidence of $\mathrm{CMB}$ on brain MRI among ICH patients in Qatar.

\section{Methods}

Our stroke database prospectively collects information on all suspected stroke in our hospital. Patients with $\mathrm{ICH}$ who underwent brain MRI were included in our study. The following MRI sequences were reviewed by 2 reviewers: SWI, phase reversal and T2 flair. The location size and distribution of MB were defined in each case.

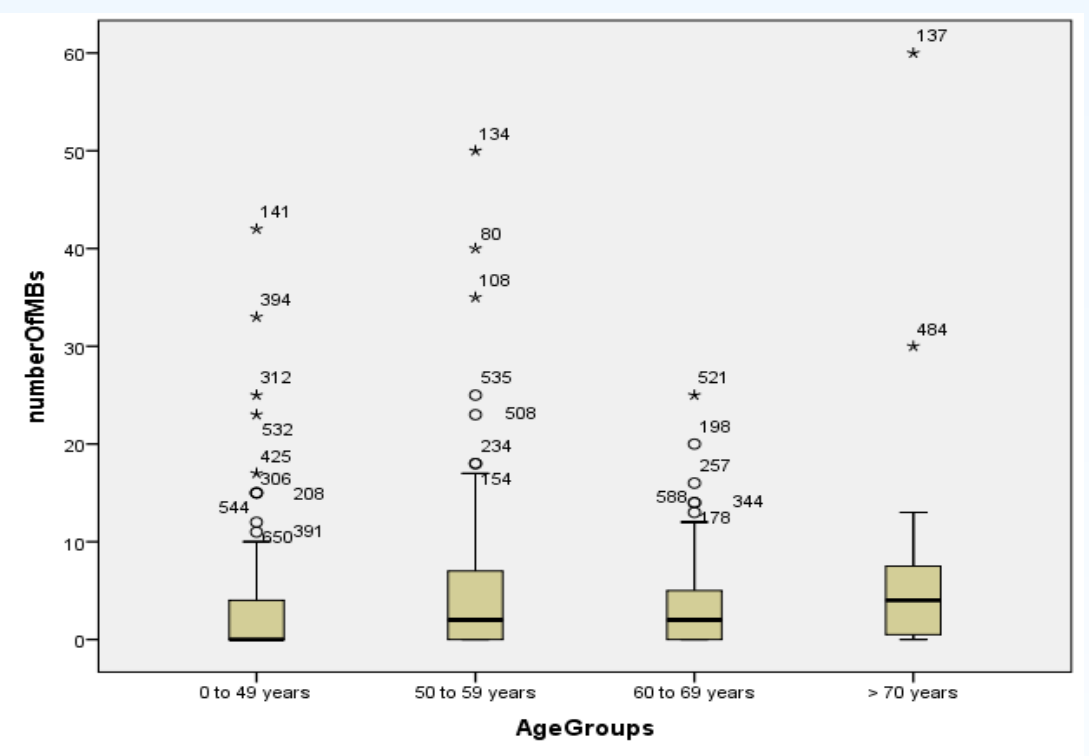

Number of microbleeds based on age groups.

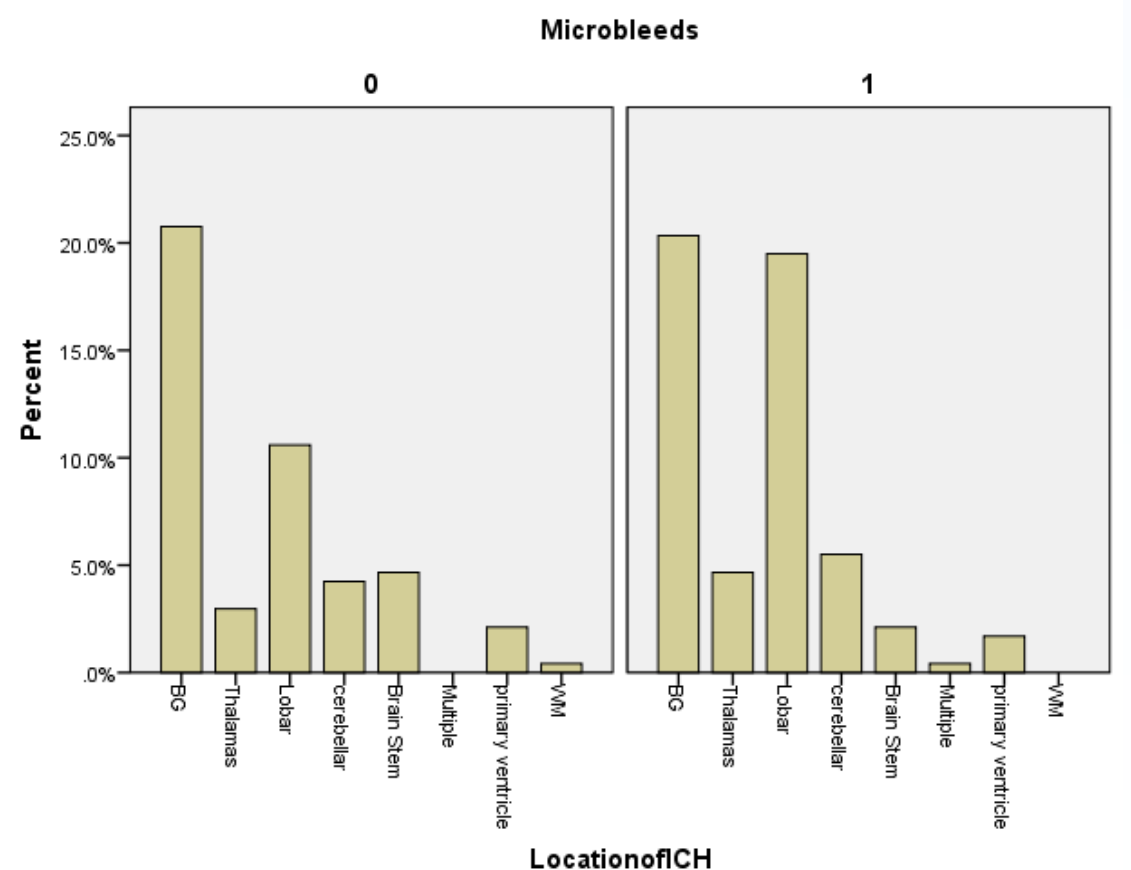

Percentage of presence of microbleeds in patient with $\mathrm{ICH}$ based on location in both males and females.

\section{Results}

584 patients were included in our analysis. Mean age 52+/-12, Sex: M/F: 497/86 (85/15\%), GCS:11+/-4, SBP 179+/-35, DBP: $102+/-26.218$ patients underwent brain MRI. CMB were evident in 119/218 cases $(55 \%)$, mean number of CMBs $9+/-10$, median 5 (IQ range: 3-11).

The distribution of CMBs was: superficial (11/119, $9 \%)$, deep $(52 / 119,44 \%)$ and diffuse $(56 / 119,47 \%)$. Macrobleeds were present in $16 / 119$ cases (13\%). CMBs mainly seen in basal ganglia $\mathrm{ICH}(45 / 119$, $38 \%)$ followed by lobar ICH (41/119,35\%). CMBs were related to hypertension $(76 / 119,64 \%)$ and possible hypertension-related (32/119, 27\%). Cerebral amyloid angiopathy was suspected in only $6 / 119,5 \%(P<0.001)$ of patients.

In the logistic regression analysis, the main risk factors for CMBs were: Hypertension (OR 2.11, C195\%:1.1-4, $\mathrm{P}=0.024)$. In addition, hypertension as an etiology of $\mathrm{ICH}$ remained the main predictor of CMBs (adjOR: 3, Cl95\%:1.3-7, $\mathrm{P}=0.013$ )

\section{Conclusion}

CMBs are very common on SWI brain MRI in $\mathrm{ICH}$ population. This may be explained by the high prevalence of hypertension in our population

\section{References}

1. Tveiten A, Ljøstad U, Mygland $\AA$, Naess $H$. Leukoaraiosis is associated with short- and long-term mortality in patients with intracerebral hemorrhage. J Stroke Cerebrovasc Dis. 2013;22:919-925.

2. Won YS, Chung PW, Kim YB, Moon HS, Suh BC, Lee YT, et al. Leukoaraiosis predicts poor outcome after spontaneous supratentorial intracerebral hemorrhage. Eur Neurol. 2010;64:253-257

3. Fazekas F, Barkhof F, Wahlund LO, Pantoni L, Erkinjuntti T, Scheltens $\mathrm{P}$, et al. CT and MRI rating of white matter lesions. Cerebrovasc Dis. 2002;13 Suppl 2:31-36. doi: 49147 